\title{
Dual-wavelength light-scattering technique for selective detection of volcanic ash particles in the presence of water droplets
}

\author{
Z. Jurányi, H. Burtscher, M. Loepfe, M. Nenkov, and E. Weingartner \\ Institute of Aerosol and Sensor Technology, University of Applied Sciences Northwestern Switzerland, Windisch, Switzerland \\ Correspondence to: E. Weingartner (ernest.weingartner@fhnw.ch)
}

Received: 6 July 2015 - Published in Atmos. Meas. Tech. Discuss.: 13 August 2015

Revised: 16 November 2015 - Accepted: 25 November 2015 - Published: 10 December 2015

\begin{abstract}
A new method is presented in this paper which analyses the scattered light of individual aerosol particles simultaneously at two different wavelengths in order to retrieve information on the particle type. We show that dust-like particles, such as volcanic ash, can be unambiguously discriminated from water droplets on a single-particle level. As a future application of this method, the detection of volcanic ash particles should be possible in a humid atmosphere in the presence of cloud droplets. The characteristic behaviour of pure water's refractive index can be used to separate water droplets and dust-like particles which are commonly found in the micrometre size range in the ambient air. The low real part of the water's refractive index around $2700-2800 \mathrm{~nm}$ results in low scattered light intensities compared to e.g. the visible wavelength range, and this feature can be used for the desired particle identification.

The two-wavelength measurement set-up was theoretically and experimentally tested and studied. Theoretical calculations were done using Mie theory. Comparing the ratio of the scattered light at the two wavelengths (visible-to-IR (infrared), $R$ value) for water droplets and different dust types (basalt, andesite, African mineral dust, sand, volcanic ash, pumice) showed at least 9-times-higher values (on average 70 times) for water droplets than for the dust types at any diameter within the particle size range of $2-20 \mu \mathrm{m}$. The envisaged measurement set-up was built up into a laboratory prototype and was tested with different types of aerosols. We generated aerosols from the following powders, simulating dust-like particles: cement dust, ISO 12103-1 A1 Ultrafine Test Dust and ash from the 2012 eruption of the Etna volcano. Our measurements verified the theoretical considerations; the median experimental $R$ value is 8-21 times higher for water than for the "dust" particles.
\end{abstract}

\section{Introduction}

Atmospheric aerosol particles absorb and scatter solar radiation and, therefore, have an effect on the Earth's radiative budget and influence our climate. To understand and be able to estimate this effect, the physical and chemical properties of the atmospheric aerosols such as e.g. number concentration, number size distribution, chemical composition, optical properties and hygroscopicity have to be better understood and determined.

Aerosol particles, illuminated by light, interact with the electromagnetic radiation and scatter light in all directions. The intensity of the scattered light in a certain direction depends on the particle's size, refractive index, shape, scattering angle and the wavelength of the incident light. The scattering behaviour of a homogenous, spherical particle can be described by Mie theory (Bohren and Huffman, 2004). It requires the wavelength of the incident light, the scattering angle, the refractive index of particle relative to the carrier medium (in our case it is air) and the particle's diameter as input, and it provides an exact solution of the differential scattering cross section. The differential cross section as a function of the particle diameter shows a distinct pattern with a rapidly fluctuating structure called Mie oscillations in the range where the particle diameter is comparable to the wavelength of the incident light.

The method of analysing scattered light from aerosol particles is a widely used aerosol measurement technique, which is mainly used for particle sizing and counting. Optical particle counters (OPCs) collect scattered light from individual particles in a defined scattering angle range in order to gain information about the optical and/or physical properties of particles (e.g. Rosen, 1964; Binnig et al., 2007). These instruments have been used to characterise aerosol particles since 
the 1940s (Kerker, 1997). The information on the scattered light intensity can be used to derive information on the size of the individual particles under certain assumptions regarding their refractive index and shape (Dick et al., 1994). For a well-defined observation volume, the frequency of encountered light pulses is used to derive the particle concentration, and with the measured size the aerosol number size distribution can be inferred.

However, as it was already mentioned before, the light scattering is also dependent on the chemical composition of the aerosol particles through the refractive index of the particles. Therefore, it is also possible to retrieve limited information on the chemical composition by measuring light scattering. Szymanski et al. (2002) and Nagy et al. (2007) have developed and investigated a dual-wavelength optical spectrometer. This instrument works with two laser sources at 532 and $685 \mathrm{~nm}$ wavelengths and four detectors collecting scattered light in forward and backward angular ranges. As a result, a set of four independently measured values from a detected particle allows the assessment of particle size and its complex refractive index.

Measuring the scattered light simultaneously at two different wavelengths can provide information on the average aerosol particle size. Assuming no strong wavelength dependence of the refractive index, the ratio of the scattered light's intensity changes with the mean particle size monotonically in the sub-micron size range. Rosen and Kjome (1991) have developed a backscatter sonde which measures simultaneously at 490 and $940 \mathrm{~nm}$ wavelengths the backscattered light around $173^{\circ}$ scattering angle, and the ratio of the red to blue backscattered light is used to estimate the mean particle size. This instrument does not measure single particles as it has an effective sensitive volume of the order of $1 \mathrm{~m}^{3}$. Inspired by this backscatter sonde, the Compact Optical Backscatter and AerosoL Detector (COBALD) was developed in 2008 using high-power LEDs at comparable wavelength for cirrus cloud analysis (Brabec et al., 2012; Cirisan et al., 2014) with a 10 -fold instrument mass reduction down to $0.5 \mathrm{~kg}$. Multi-wavelength lidar measurements have shown that different aerosol types (biomass burning, Saharan dust, marine aerosol and anthropogenic pollution) have different backscatter ratios measured at 532 and $1064 \mathrm{~nm}$ wavelengths (Groß et al., 2013).

In this paper, we introduce a method where also two monochromatic light sources are used and backscattered light is measured over a defined angular range for each wavelength. By selecting the correct specific wavelengths and detection angles, the ratio of the scattered light intensities can be used for component-specific particle differentiation. The new approach is to select one wavelength such that a particular optical property of a certain particle type can be used for the envisaged particle differentiation. In our application, the specific optical characteristics of water in the infrared (IR) wavelength range is used to distinguish water droplets from dust particles such as volcanic ash.
Volcanic ash aerosol might be present in the atmosphere if emitted through volcanic eruptions. If the eruption is strong enough, the volcanic ash cloud can reach altitudes of aviation and be a serious security risk to airplanes. It can severely damage jet engines and endanger passenger transportation (Casadevall, 1993). Such an event might therefore make it necessary to close down airports and airspaces. For example, the eruptions of the Eyjafjallajökull volcano in Iceland in April and May in 2010 resulted in partial closure of Europe's airspace for several days. The volcanic ash particles are usually found in the micrometre diameter range. After the eruption of the Eyjafjallajökull volcano, the measured volcanic ash volume size distribution had a mode around $3 \mu \mathrm{m}$ (Bukowiecki et al., 2011) measured at the high-alpine research station Jungfraujoch, Switzerland, while two distinct research aircrafts have measured 3.5 and $10 \mu \mathrm{m}$ (Turnbull et al., 2012). Further information on the volcanic ash properties can be found in other publications (Schumann et al., 2011; Weinzierl et al., 2012).

Volcanic ash particles are not the only particles in the above-mentioned micrometre size range. Fortunately, the normal background dry-aerosol mass concentration in the free troposphere is negligible (only a few $\mu \mathrm{g} \mathrm{m}^{-3}$; e.g. Cozic et al., 2008) when compared to the lower limit established for the area of low volcanic ash contamination $\left(0.2 \mathrm{mg} \mathrm{m}^{-3}\right)$. In the presence of substantial water in the atmosphere the situation can be different; cloud droplets are also found in the supermicron size range, and their mass/number concentration can easily reach the limit values established by the existing legislation for volcanic ash.

One optical method to distinguish between water droplets and volcanic ash particles is the measurement of the scattered light's polarisation ratio. Whether a particle is spherical or not can be detected using linearly polarised incident light and detecting the polarisation state of the scattered light (Kobayashi et al., 2014). Spherical water droplets do not change the polarisation state, whereas non-spherical particles such as volcanic ash scatter the light depolarised (Muñoz and Hovenier, 2011), which results in a decrease of the scattered light intensity in the original polarisation plane and an increase in the perpendicular polarisation plane.

The Back-scatter Cloud Probe (BCP) from Droplet Measurement Technologies (Beswick et al., 2014) with the optional polarisation detection is a commercial instrument which uses this method.

The BCP uses a single wavelength of $658 \mathrm{~nm}$ and measures the scattered light of single particles at a solid angle range of $144-156^{\circ}$. This lightweight instrument is able to detect particles with optical diameters in the range of 5-75 $\mu \mathrm{m}$. If this instrument is equipped with the optional polarisation detector, the polarisation ratio of the measured particles indicates whether the particle is spherical or not. With this feature, it might be possible to differentiate between water droplets and significantly non-spherical volcanic ash particles. 
The Cloud and Aerosol Spectrometer with Polarization (CASPOL) is another new instrument to characterise atmospheric aerosols. It measures the aerosol light scattering (at one wavelength) in forward and backward directions, with an additional polarised detector in the backward direction. Glen and Brooks (2013) have shown that it can characterise optical properties of various dust particles on a particle-by-particle basis.

Here we introduce a new method which is based on dualwavelength scattered light measurement and is able to distinguish between water droplets and other particles of dust origin.

\section{Theory}

The proposed component-specific particle differentiation is based on the different scattering behaviour of these components at least at one of the two wavelengths. This particular behaviour results in a significantly different value if the ratio of the scattered light intensity at the two different wavelengths is calculated (as a function of the particle diameter). The ratio $R$ is defined as follows:

$R\left(\lambda_{1}, \lambda_{2}, D\right)=\frac{\mathrm{d} C\left(\Theta_{1}, D, m_{1}, \lambda_{1}\right) / \mathrm{d} \Omega}{\mathrm{d} C\left(\Theta_{2}, D, m_{2}, \lambda_{2}\right) / \mathrm{d} \Omega}$

where $\lambda_{1}$ and $\lambda_{2}$ are the selected wavelengths, $\frac{\mathrm{d} C}{\mathrm{~d} \Omega}$ is the differential scattering cross section of the aerosol particle, $m_{1}$ and $m_{2}$ are the complex refractive indices of the aerosol particles at $\lambda_{1}$ and $\lambda_{2}, D$ is the diameter of the aerosol particle and $\Theta$ is the scattering angle. If the particles are spherical, $\frac{\mathrm{d} C}{\mathrm{~d} \Omega}$ can be exactly calculated using the Mie theory (Bohren and Huffman, 2004). It can be experimentally determined as well as the ratio of the measured scattering signals at the two wavelengths.

With this, if the scattered light intensities of individual particles are measured simultaneously at both wavelengths, the particle differentiation will become possible because the ratio $R$ depends on the particle chemical composition. If needed, the particles can be not only counted but also sized based on the scattered light's intensity at one of the wavelengths using the same method as traditional optical particle counters. In the following we will show an application of this method which intends to separate water droplets from "dust" particles. Under "dust" particles, we understand aerosol particles in the $\mu \mathrm{m}$ size range of various origins: different kinds of mineral dust, road dust or particularly volcanic ash. For the particle differentiation, we use the unique optical behaviour of water, and at the same time we assume the lack of the same in the case of the dust particles. In order to demonstrate the selectivity, we compare the $R$ ratios of water at these two wavelengths with those of several dusts.

Figure 1 shows the real and imaginary part of the water droplets' refractive index as a function of the wavelength of light (Rothman et al., 2013). The distinct absorption of wa-

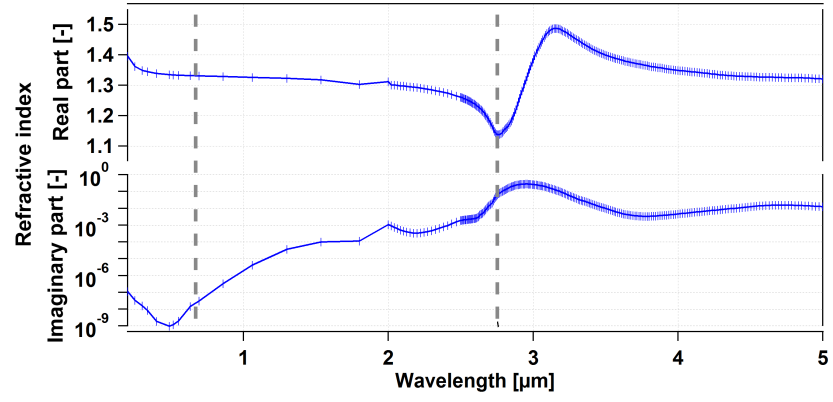

Figure 1. Real and imaginary part of the refractive index of water as a function of wavelength (Rothman et al., 2013); the dashed grey lines show our two selected wavelengths of 660 and $2750 \mathrm{~nm}$.

ter at $\lambda=3 \mu \mathrm{m}$ is seen in an elevated imaginary part of the refractive index and consequently in a distinct change in the real part. We use this behaviour to get a significantly different scattering behaviour of water compared to other aerosol components which might be present in the ambient air. For the experimental set-up we have chosen $\lambda_{1}=660 \mathrm{~nm}$ in the visible wavelength range and $\lambda_{1}=2750 \mathrm{~nm}$ in the IR as a wavelength combination where water has significantly different refractive indices (see the grey dashed lines in Fig. 1).

In Table 1 we have summarised the refractive indices of water and several "dust-like" aerosols at the two selected wavelengths. We used these literature values to calculate the $R$ ratios and to simulate the performance of a dust/waterspecific optical particle counter. Water has significantly different refractive index values at $\lambda_{1}$ and $\lambda_{2}$, whereas the same for the dust-like components do not change significantly between the selected wavelengths.

\subsection{Mie calculations}

The differential scattering cross sections of the particles were calculated using a custom-written Mie code assuming unpolarised incident light. The choice of doing the calculations with unpolarised incident light might not be correct since lasers often emit highly polarised light. However, for our selected size and wavelength ranges we found that the polarisation has only a limited influence on the $R$ values, and this is the reason why the effect of the polarisation was not considered and investigated further. Figure 2 shows the modelled scattered light intensity ratio $R$ for water, ice and dust particles as a function of the particle's diameter in the $2-20 \mu \mathrm{m}$ size range. $R\left(\lambda_{1}, \lambda_{2}, D\right)$ is calculated following Eq. (1), averaging the differential cross sections over the scattering angle ranges of $130-150$ and $140-160^{\circ}$, which simulates the employed optical measurement system with a non-zero detector opening angle. We have chosen to detect the backscattered light because the envisaged instrument application in the field aims at ambient stationary and aircraft-deployed measurements. The low real part of the refractive index of water at $2750 \mathrm{~nm}$ compared to $660 \mathrm{~nm}$ is reflected by high 
Table 1. The refractive index of water, ice and different dust types at 660 and $2750 \mathrm{~nm}$ wavelength.

\begin{tabular}{llll}
\hline Aerosol type & $\begin{array}{l}\text { Refractive index } \\
\text { at } 660 \mathrm{~nm} \mathrm{[-]}\end{array}$ & $\begin{array}{l}\text { Refractive index } \\
\text { at 2750 nm [-] }\end{array}$ & Reference \\
\hline Water droplets & $1.33+1.9 \times 10^{-8} \mathrm{i}$ & $1.14+5.9 \times 10^{-2} \mathrm{i}$ & Rothman et al. (2013) \\
Ice & $1.31+1.8 \times 10^{-8} \mathrm{i}$ & $1.14+7.4 \times 10^{-3} \mathrm{i}$ & Rothman et al. (2013) \\
Basalt & $1.52+1.1 \times 10^{-3} \mathrm{i}$ & $1.50+3.5 \times 10^{-3} \mathrm{i}$ & Pollack et al. (1973) \\
Andesite & $1.47+1.6 \times 10^{-3} \mathrm{i}$ & $1.46+5.0 \times 10^{-3} \mathrm{i}$ & Pollack et al. (1973) \\
African mineral dust & $1.55+3.0 \times 10^{-4} \mathrm{i}$ at $700 \mathrm{~nm}$ & $1.50+1.0 \times 10^{-2} \mathrm{i}$ & Di Biagio et al. (2014) \\
& & & Petzold et al. (2011) \\
Sand & $1.53+4.5 \times 10^{-3} \mathrm{i}$ & $1.52+2.7 \times 10^{-2} \mathrm{i}$ & Koepke et al. (1997) \\
Volcanic ash & $1.57+0 \mathrm{i}$ & $1.51+3.6 \times 10^{-2} \mathrm{i}$ & Grainger et al. (2013) \\
Pumice & $1.46+1 \times 10^{-2} \mathrm{i}$ & $1.50+8.0 \times 10^{-3} \mathrm{i}$ & Volz (1973) \\
\hline
\end{tabular}

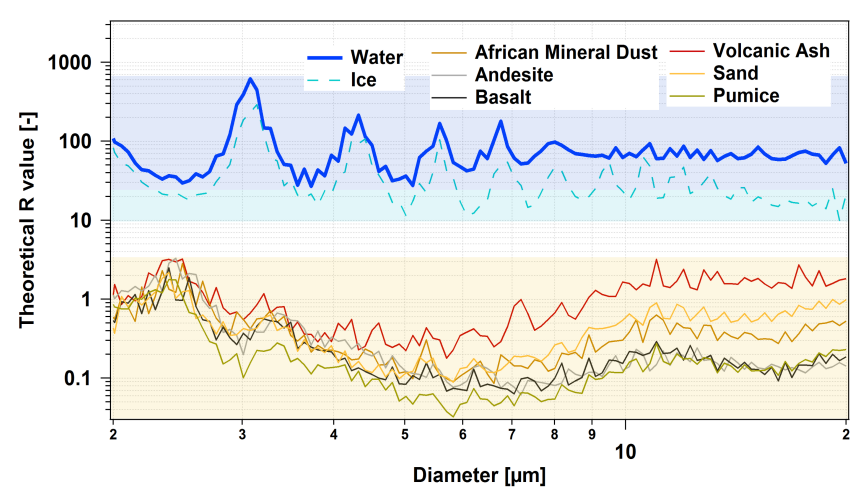

Figure 2. The theoretical $R$ values at $\lambda_{1}=660 \mathrm{~nm}$ and $\lambda_{2}=$ $2750 \mathrm{~nm}$ as a function of the particle diameter for different types of aerosols.

$R\left(\lambda_{1}, \lambda_{2}, D\right)$ values with an average of $\sim 70$ compared to an average $R$ of $\sim 0.15-0.9$ for different dust types. The bands of the different ratio values of water (blue shading in Fig. 2) and dust particles (orange shading in Fig. 2) are well separated at any particle diameter of interest; the diameter where $R$ values are the least separated is around $2.5 \mu \mathrm{m}$, but even here there is approximately a factor of 9 between water and dust. The refractive index of ice slightly differs from the one of liquid water, and therefore the $\mathrm{R}$ values (dashed turquoise line in Fig. 2) are somewhat lower as well with an average value of $\sim 30$, which is still much higher than the one for dust, and there is no overlap between the single $\mathrm{R}$ value ranges either (turquoise and orange shading in Fig. 2).

As mentioned before, we used Mie calculation to model the scattered light from dust particles, which assumes homogeneously composed spherical particles. However, dust particles are often non-spherical (e.g. Coz et al., 2010) and, therefore, their light-scattering properties can differ from the values that are calculated using the Mie theory. Curtis et al. (2008) studied the light-scattering properties of many representative dust aerosol components and found that a significant deviation between Mie theory calculation and measure- ment exists. Especially for non-clay minerals, Mie calculations overestimate the backscattering signal by up to a factor of 2 in the angle range of our interest $\left(130-160^{\circ}\right)$. Next to this, our knowledge of the refractive indices of the different dust-like components (Petzold et al., 2011, and references therein) are still quite uncertain; the literature values of the imaginary part of the complex refractive index varies from $<1 \times 10^{-3}$ to 0.01 at a wavelength of $550 \mathrm{~nm}$ for mineral dust particles. However, as we see from Fig. 2, even if we underestimate the scattering signal ratios by multiple factors, the $R$ values for water and dust particles will be still different enough to have the possibility of a proper differentiation. The effect of the particle's non-sphericity on the theoretical calculations is investigated in the next section.

\subsection{The effect of non-sphericity}

In this section we show some examples of how the nonsphericity of dust-like particles influences our calculations. We do not know the exact, non-spherical shape of the particles, which, of course, differs from particle to particle as well. Therefore, the following assumptions were made: the shape of the non-spherical particles was chosen to be ellipsoid, because in a recent publication (Merikallio et al. , 2015) it was shown that the light-scattering properties of volcanic ash particles can be well described assuming a particle population with different ellipsoid forms. Due to the complexity and the very high computational time demand of the problem, we were only able to calculate a few examples. For this calculation, we have used the open-source, discrete-dipoleapproximation code from Yurkin and Hoekstra (2011). We did the calculations for five different ellipsoid shapes, all having a volume equivalent diameter of $5 \mu \mathrm{m}$, and we have investigated the influence of the particle orientation on the scattering with the help of one of these ellipsoids having axis ratios of 1.25 and 2 as well. The $R$ values were calculated following Eq. (1), using the same refractive indices as for the volcanic ash Mie calculations (see Table 1) and the same scattering angle ranges. We have chosen the $z$ axis as the direction of the incident light propagation. The obtained results and the 
Table 2. The ellipsoids used as examples of how the nonsphericity influences the light-scattering calculations and with that the $R$ value. $X, Y$ and $Z$ are the double lengths of the semi-axes; $\alpha, \beta$ and $\gamma$ define the orientation of the particles, in terms of how much the axes attached to the particle are rotated, first by $\alpha$ over the $z$ axis, then by $\beta$ over the $y$ axis and lastly by $\gamma$ over $z^{\prime}$, the new position of the $z$ axis. The propagation of the incident light is along the $z$ axis.

\begin{tabular}{rrrrrrr}
\hline$X[\mu \mathrm{m}]$ & $Y[\mu \mathrm{m}]$ & $Z[\mu \mathrm{m}]$ & $\alpha\left[^{\circ}\right]$ & $\beta\left[^{\circ}\right]$ & $\gamma\left[^{\circ}\right]$ & $R$ value $[-]$ \\
\hline 5 & 5 & 5 & 0 & 0 & 0 & 0.24 \\
5.57 & 4.74 & 4.74 & 0 & 0 & 0 & 0.95 \\
7.94 & 3.97 & 3.97 & 0 & 0 & 0 & 0.63 \\
6.79 & 5.43 & 3.39 & 0 & 0 & 0 & 1.84 \\
4.50 & 4.95 & 5.62 & 0 & 0 & 0 & 0.37 \\
3.68 & 4.60 & 7.37 & 0 & 0 & 0 & 3.00 \\
3.68 & 4.60 & 7.37 & 90 & 0 & 0 & 4.67 \\
3.68 & 4.60 & 7.37 & 0 & 90 & 0 & 2.62 \\
3.68 & 4.60 & 7.37 & 0 & 60 & 60 & 1.90 \\
3.68 & 4.60 & 7.37 & 0 & 90 & 90 & 0.25 \\
\hline
\end{tabular}

shape and orientation of the particles are summarised in Table 2 .

Changing the particle shape from spherical to ellipsoid increases the visible light-scattering compared to the IR and as a consequence increases the $R$ value. Among our examples, the highest $R$ value of 3.00 was found for a highly non-spherical ellipsoid with axis ratios of 1.25 and 2. This $R$ value is more than 10 times higher than the value of an equivalent sphere having the same volume. The effect of the particle orientation was investigated on this ellipsoid, and the derived $R$ values of the rotated ellipsoid can also be found in Table 2. As expected, the orientation of the particle influences the $R$ value as well; however, this effect seems to be still moderate for our chosen examples: we see both increase and decrease in the $R$ values. The encountered highest $R$ value is 4.67, which is almost a factor of 20 higher than for the equivalent sphere. However, if we look at Fig. 2, we see that the $R$ value of the spherical water droplets is $\sim 35$ and, therefore, a differentiation should still be possible for non-spherical dust particles. Of course we cannot exclude that dust particles at other sizes and/or with exotic shapes will not have $R$ values in the range where water droplets are found. However, we believe that the fraction of these particles is negligible compared to the number of the total dust particles and that a successful particle differentiation using these two wavelengths is possible. In the following we will experimentally investigate the problem of the water droplet and dust-like particles differentiation.

\section{Experimental}

To verify the theoretical results we built an experimental setup to generate dust and water particles and a system for the two-wavelength light-scattering measurement.

\subsection{Particle generation}

During the experiments, we used two different methods for aerosol generation. The powder-based samples were brought into the aerosol phase with the help of a small-scale powder disperser (SSPD, TSI 3344). The powder was distributed on a round table which turns with a controllable speed below a capillary tube with a venturi aspirator. Particles are sucked up from the turntable by the low pressure that is caused by the high air velocity in a venturi tube and transmitted further by the airflow. The aerosol exits the SSPD at 5-20 $\mathrm{dm}^{3} \mathrm{~min}^{-1}$ flow rate, the particle concentration can be varied by placing more or less powder on the turntable and/or by changing its angular velocity.

The water droplets were generated by a nebuliser, filled with tap water as the particle source. The generated droplets were injected into a humidified $(\mathrm{RH}>90 \%)$ airstream at $5 \mathrm{dm}^{3} \mathrm{~min}^{-1}$ flow rate in order to accelerate and transport the droplets to either the size distribution or the optical measurement. The length of the transport tubes was as short as possible $(<20 \mathrm{~cm})$ in order to minimise the evaporation losses and the shrinking of the droplets.

\subsection{Size distribution measurements}

The particle number size distribution was measured with an aerodynamic particle sizer (APS, TSI 3321) in the aerodynamic diameter range of $0.7-20 \mu \mathrm{m}$. This instrument sizes the aerosol particles by measuring the time of flight of the individual particles in an accelerating flow field. The total flow rate of the APS was $5 \mathrm{dm}^{3} \mathrm{~min}^{-1}$ at $1 \mathrm{dm}^{3} \mathrm{~min}^{-1}$ aerosol flow rate. In order to minimise evaporation artefacts during the water droplet number size distribution measurements, sampling lines with equal particle residence times were used to deliver the droplets from the nebuliser to the instruments.

\subsection{Optical measurement set-up}

Based on the theoretical calculations, a laboratory optical measurement set-up was realised to test our theoretical considerations. The experimental set-up (an illustration is shown in Fig. 3) is an "open set-up" where ambient light can reach the detectors. It was built on an optical table of $60 \mathrm{~cm} \times 60 \mathrm{~cm}$. The visible light source is a $660 \mathrm{~nm}$ laser diode with collimation optics; the power of this laser was set such that the incident visible light power reached values of $\sim 20 \mathrm{~mW}$ at the particle detection volume during the measurements. This power was checked manually before and after each experiment with a power meter.

The IR laser is a semiconductor disk laser module, operating at $2750 \mathrm{~nm}$ wavelength, and has a maximal power of $\sim 90 \mathrm{~mW}$. The laser was developed at the Fraunhofer Institute for Applied Solid State Physics in Freiburg, Germany (IAF). The power of this laser was also checked before and 


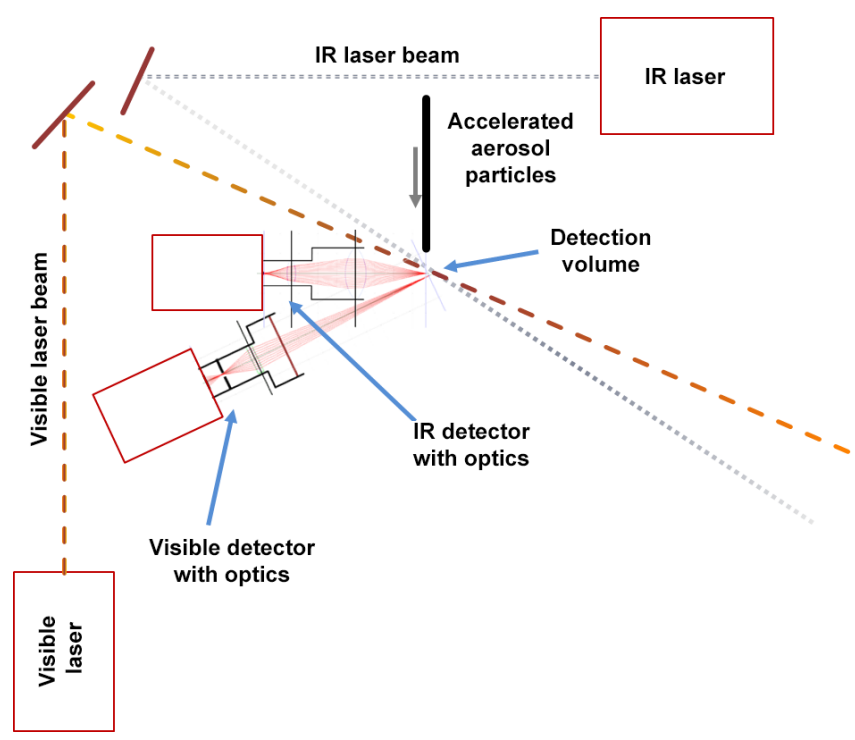

Figure 3. Drawing of the dual-wavelength optical measurement setup.

after each experiment. The IR radiation is collimated with $\mathrm{BaF}_{2}$ lenses.

Both collimated laser beams are directed to a common detection volume of $\sim 1-3 \mathrm{~mm}^{3}$. The beam adjustment is achieved by mirrors (gold for the IR and silver for the visible laser) held by tiltable and rotatable precision mirror mounts.

The scattered visible light is detected by a Hamamatsu photomultiplier (H7711-04) under $140^{\circ}$ central scattering angle with $\sim \pm 3^{\circ}$ opening angle. Due to the relatively large size and asymmetric form of the sensitive detector area $(4 \mathrm{~mm} \times 20 \mathrm{~mm})$, an iris with $0.8 \mathrm{~mm}$ hole diameter was placed between a lens (N-BK7 bi-convex, $12.7 \mathrm{~mm}$ diameter, $20 \mathrm{~mm}$ focal length) and the detector to strictly limit the detection angle. This ensures that predominately the light scattered by the particles in the joint illuminated volume is detected. To minimise the detected background light, a bandpass filter $(660 \mathrm{~nm}$ middle wavelength and $10 \mathrm{~nm}$ full width at half maximum) was placed in front of the visible detector.

In the visible wavelength range, affordable, commercial photodetectors exist (photomultipliers, avalanche photodiodes) that are able to detect light levels as low as a single photon. Unfortunately, such a technique is not yet commercially available in the IR range. The scattered IR light was measured by a VIGO PV-4TE photovoltaic IR detector under $150^{\circ}$ central scattering angle $\left( \pm 10^{\circ}\right)$, optimised to measure at $\sim 3 \mu \mathrm{m}$ wavelength. This detector has a built-in fourstage thermoelectric cooler, which cools down the detector to $195 \mathrm{~K}$ in order to reduce the detector's noise and increase its responsivity. The detector module has a built-in preamplifier with a $100 \mathrm{~Hz}-1 \mathrm{MHz}$ bandwidth. The collection and focusing optics included two bi-convex $\mathrm{CaF}_{2}$ lenses with 12.7 and $25.4 \mathrm{~mm}$ diameters and 20 and $25.4 \mathrm{~mm}$ focal lengths, respectively. A bandpass filter was not used here because no significant IR background light could be encountered in the laboratory.

The measurement set-up requires highly precise adjustment of both lasers and the detectors in order to have a joint detection volume which is imaged by both detectors. Therefore, both detectors were placed on pitch and yaw platforms with micrometre screws. The measured voltage signals from the detectors are digitised by a National Instruments PCI card (NI 5112) built into a PC. The voltage peaks resulting from particles flying through the instrument's detection volume were identified, sized and saved using custom-written LabVIEW software.

Data from the detectors were recorded with $1 \mathrm{MHz}$ time resolution, and every second $10^{6}$ data points per detector were analysed. The voltage peaks caused by single-particle scattering have to be separated from the detector noise. Therefore only peaks with maximal voltage values exceeding a certain threshold are considered. The baseline of the detectors can change with time, because e.g. the ambient light reaching the visible detector changes as well. This is the reason why we define a new peak threshold for every $1 \mathrm{~s}$ data series. It is assumed that the detector baselines remained constant within these $1 \mathrm{~s}$ measurement periods and were identified as the median of all the voltage values. Due to the set-up and alignment of the two lasers and the detectors, the detection volumes are not entirely identical for both wavelengths. Therefore, some of the particles are only detected by one of the detectors and not by the other. We only considered the coincident events (i.e. the peaks that appear simultaneously in both detectors). In practice, this was achieved by selecting the peaks that are timely separated by less than half of a peak width. As mentioned below, concentrations were chosen such that the probability of two particles being at the same time in the detection volume is negligible.

Figure 4 illustrates our threshold selection. One second of detector background data was simulated with Gaussian noise around a median value of $0.05 \mathrm{~V}$ with a standard deviation of $0.01 \mathrm{~V}$. These values were chosen to match the experienced real values the best. The histogram of the detector signal without aerosol particles passing by is shown as a solid green line in Fig. 4. The other coloured lines show the detector signal histograms if a different number (blue: $1.5 \%$; purple: $4 \%$; orange: $10 \%$ of the total data points containing data from a scattered light peak) of peaks were added to the background. Panel a of Fig. 4 shows a short segment of the data. The peaks are randomly distributed in time, having a Gaussian form with a standard deviation of 10 points $(10 \mu \mathrm{s})$. The peak amplitudes were chosen to be exponentially distributed with $1 \mathrm{~V}$ average and standard deviation. These parameters were chosen to simulate the obtained results well. Our aim was to define a threshold, based on the data points' histogram which is not significantly influenced by the number of the detectable peaks. As one can see in Fig. 4, the medians and the 75th percentiles (vertical coloured, solid lines) of the distributions are only slightly influenced by the number of added 

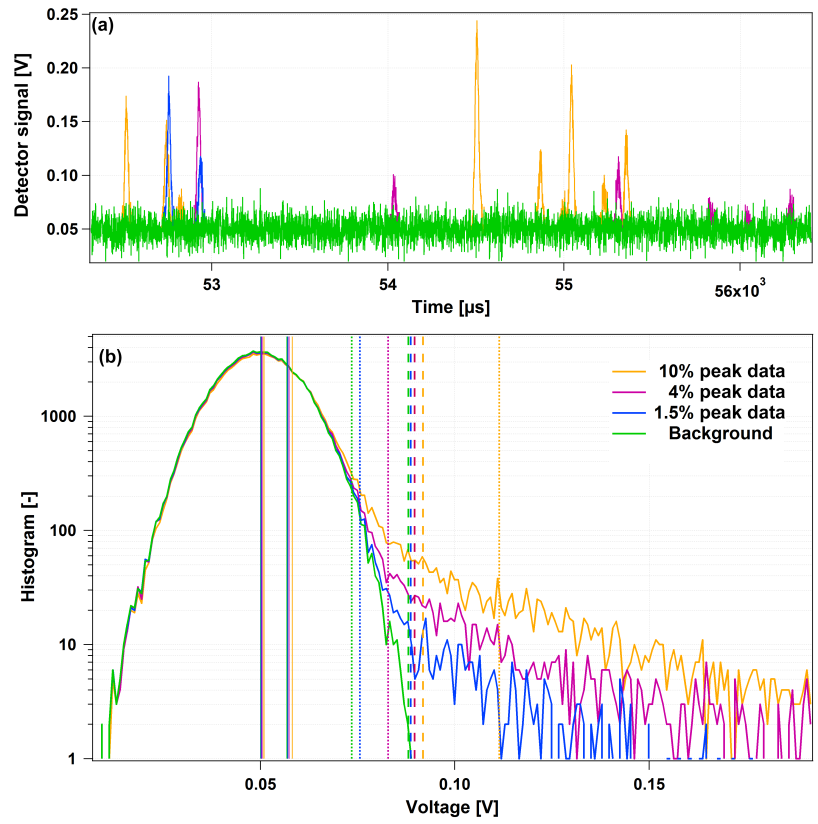

Figure 4. Simulated detector signal data without (green lines) and with a different number of particle peaks (blue, purple and orange lines). Panel (a) shows a short segment of the simulated data, whereas panel (b) shows the histograms of the data points on a logarithmic scale as a function of the detector voltage signal. See the text for details on the meaning of the vertical lines.

peaks, whereas the 99th percentiles (vertical dotted lines) are highly influenced. Therefore a high percentile value cannot be used as a threshold for identifying the particle peaks. We have defined the threshold as a constant factor $C$ times the difference between the 75th percentile and the median, added to the median value. These values are also shown in Fig. 4 as dashed, vertical lines. At the highest peak occurrence $(10 \%$ of the data points contain peak values) this threshold is $4 \%$ higher than for the background case, whereas for the other two examples the difference is less than $2 \%$. For the optical experiments, the factor $C$ was chosen to be 3.4. The peaks exceeding this threshold are identified as particle peaks and are sized. The position (time) and amplitude of each peak are saved as a text file for further data analysis.

\section{Experimental results}

During the laboratory measurements next to the water droplets the following dust powders were used to simulate a variety of different atmospheric dust types: cement dust (commercial Portland cement), ISO 12103-1 A1 Ultrafine Test Dust (Powder Technology Inc.) and ash from the 2012 eruption of the Etna volcano. Particle number size distribution measurements were performed in addition to the optical measurements. Figure 5 shows these measured number size distributions of the different generated aerosols. The
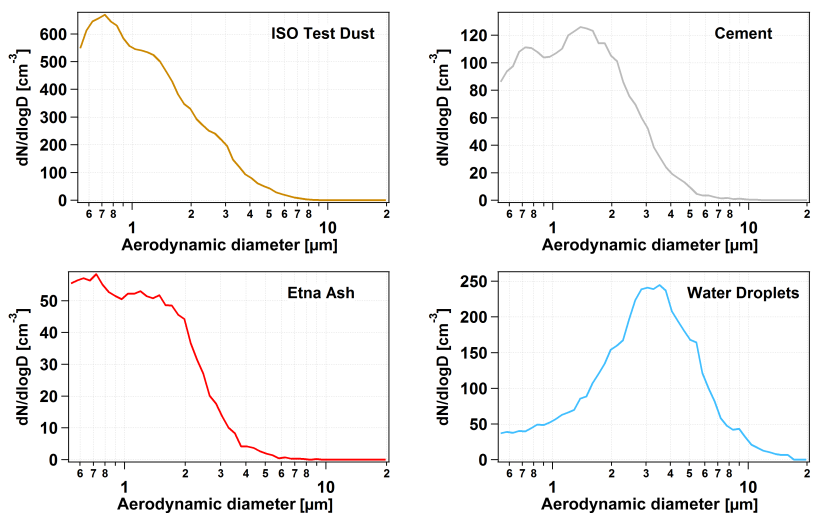

Figure 5. Typical number size distributions of the different aerosol types as a function of the aerodynamic particle diameter measured with an APS.

generated dust aerosol particles had 1.38, 1.41 and $1.58 \mu \mathrm{m}$ mean aerodynamic diameter for Etna ash, ISO test dust, and cement, respectively. The water droplets were significantly larger in size with $3.45 \mu \mathrm{m}$ mean diameter.

For each optical experiment, $2 \times 10^{3}-10^{5}$ individual particles were measured which were detected as coincident peaks in both detectors. The particle concentration was low (fewer than $\sim 200$ particles $\mathrm{s}^{-1}$ ) such that no coincidence artefacts were encountered. This means that on average less than $1 \%$ of the data points contained particle-generated peaks. The dust particle measurements was conducted at a flow rate of $20 \mathrm{dm}^{3} \mathrm{~min}^{-1}$, which corresponds to an average air exit velocity of $\sim 30 \mathrm{~m} \mathrm{~s}^{-1}$ and $\sim 50 \mu$ s average peak width. The corresponding average peak width and flow rate for the water droplet experiments were $\sim 200 \mu$ s at $5 \mathrm{dm}^{3} \mathrm{~min}^{-1}$, respectively.

The $R$ ratio for individual particles was calculated by dividing the peak amplitude voltage measured by the visible detector by the same value measured by the IR detector. This experimental $R_{\text {exp }}$ value is not equal to the theoretical one, since the experimental set-up was not calibrated for the different detector efficiencies, numerical apertures, incident laser intensities and optical losses. This is the reason why the experimental and the theoretical $R$ values are connected by a constant factor, which does not depend on the measured particle type.

Even for monodisperse aerosol particles, many different $R_{\exp }$ values are expected because of the different laser beam shapes at their overlapping region, and therefore it must be expected that, for example, a particle crosses one laser close to its intensity maximum and the other laser at the border at lower intensities. As a consequence, a distribution of $R$ values is encountered.

For this reason we do not evaluate the $R$ ratios of the individual particles but rather interpret their probability distribution. Figure 6 shows these probability distributions, as measured for the different aerosol types. The solid lines show 
Table 3. Median experimental and theoretical $R$ values for water and some dust types.

\begin{tabular}{lrrr}
\hline Aerosol type & \multicolumn{3}{c}{ Median of the $R$ value } \\
& Experimental & Theoretical, $D>1 \mu \mathrm{m}$ & Theoretical, $D>2 \mu \mathrm{m}$ \\
\hline Cement dust & 15 & - & - \\
ISO test dust & 17 & 3.2 & 0.6 \\
Etna volcanic ash & 41 & 3.8 & 1.0 \\
Water droplets & 308 & 59.2 & 58.9 \\
Water-to-dust ratio & $8-21$ & $16-19$ & $60-99$ \\
\hline
\end{tabular}

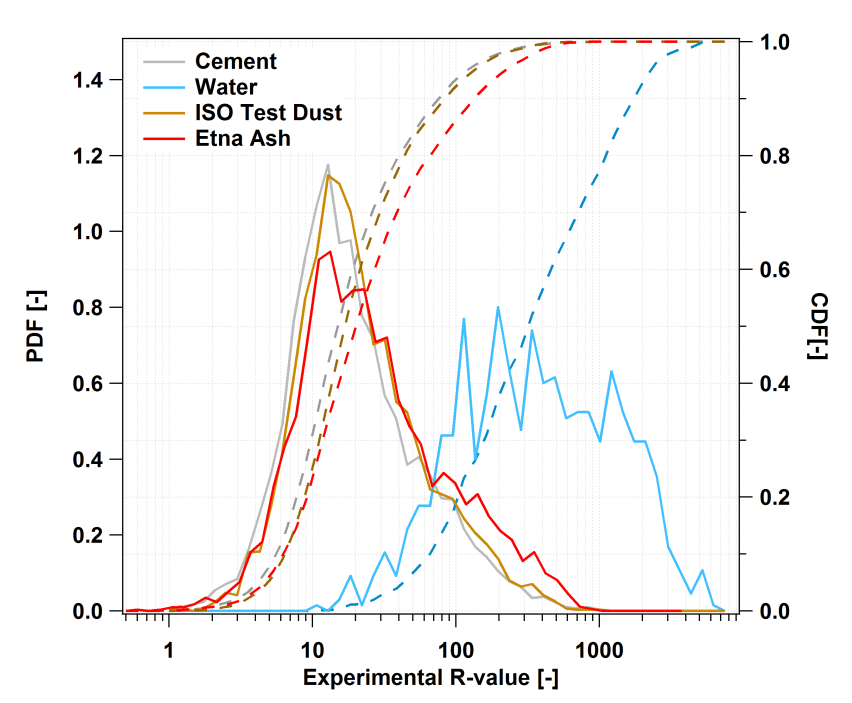

Figure 6. Measured probability density functions (left axis, solid lines) and cumulative density functions (right axis, dashed lines) of $R$ values for water droplets and different dust-like aerosols.

the probability density functions (left axis); the dashed lines show the cumulative density functions (right axis). As we have expected from the theoretical considerations, the $R$ values of water droplets are shifted to significantly higher values (please note the logarithmic $x$ axis of Fig. 6) compared to the $R$ values of dust particles. The median $R$ values for the different particle types are also shown in Table 3 . We found that the median was 8-21 times higher for water than for the various dust types. With this, our hypothesis of a dualwavelength light-scattering instrument being able to differentiate between specific components is verified.

Table 3 also shows modelled $R$ values that were calculated for water, ISO test dust and volcanic ash. Cement was not included in these calculations because we had no information about its refractive index at $2750 \mathrm{~nm}$ wavelength. The refractive index of ISO test dust was assumed to be equal to the value of African mineral dust in Table 1 . The $R$ value calculations also used the measured number size distributions as input and assumed a minimal detection limit of the optical system of either 1 or $2 \mu \mathrm{m}$ particle diameter. The theoretical estimations of the $R$ values cannot be directly com- pared to the measurement values because the optical measurement set-up was not calibrated with respect to detector efficiencies, incident laser intensities, and optical transmissions. However, a comparison of the relative change in measured and modelled $R$ values (water-to-dust $R$ value ratio, last row of Table 3 ) is possible as these are not affected by the above-mentioned calibration coefficients. Measurements show that $R$ values of water are a factor of 8-21 higher than for the dust particles. The calculated increase lies between a factor of 16-99 and is dependent on the component and on the smallest detectable particle size. We consider this as a reasonably good agreement bearing all the different uncertainties in mind, such as the ill-defined lower size cut (size of the smallest detectable particle), the non-sphericity of the dust aerosols, the different components considered during calculations and measurement, and the restricted knowledge on the refractive index of the different dust particles.

\section{Conclusions}

We have built and tested (theoretically and experimentally) a laboratory prototype of an aerosol measurement instrument which detects backscattered light at two different wavelengths simultaneously from single particles at 660 and $2750 \mathrm{~nm}$. This measurement set-up aims successfully for the separation of water droplets and dust particles such as volcanic ash. We use the visible-to-IR scattered light intensity ratio ( $R$ value) as an indicator to decide if the detected particle is a water droplet or not. The low light scattering of water at $2750 \mathrm{~nm}$ compared to the visible range results in high $R$ values for water droplets.

We modelled the $R$ values for water droplets and different kinds of dust particles (basalt, andesite, African mineral dust, sand, volcanic ash, pumice) using Mie theory in the particle size range of $2-20 \mu \mathrm{m}$ and found as we expected that at any size the $R$ ratios of water are factors higher (on average 70) than the ones for the dust types. We have also built up a laboratory measurement set-up to practically test our method. With the current experimental set-up, we were only able to compare statistically the visible-to-IR scattering ratios since particles were experiencing different incident laser intensities due to the different laser beam profiles. We have shown that the experimental median $R$ value is $8-21$ times higher 
for water than for the various aerosol types we used for dust simulation (cement, ISO test dust and volcanic ash).

In the future, the measurement set-up will be modified such that the problem originating from the incident light intensity's inhomogeneity will be minimised. If we combine the two laser beams having the same beam diameter and centre position with a suitable dichroic mirror, then the particles crossing the lasers will experience the same fraction of the maximal, central incident laser intensities, and, therefore, much narrower $R$ value distribution is expected. The size dependence of the single-particle scattering at the visible wavelength can be used for particle sizing. However, the incident laser power inhomogeneity (laser profile) is a problem. Applying a similar inversion algorithm as done for the $\mathrm{BCP}$ (Beswick et al., 2014) is a possibility to make quantitative particle sizing possible in the future.

A new prototype of the instrument will be developed which is deployable for stationary, ambient measurement and on aircrafts as well. During these ambient tests, the measurement set-up will be tested not only for the separation of water droplets and dust particles but also for the distinction of ice crystals. Our theoretical calculations show that with a slightly different IR wavelength of $2790 \mathrm{~nm}$ an even better discrimination of dust and ice/water is possible.

Acknowledgements. This work was supported by the Swiss Federal Office of Civil Aviation. We would like to thank the Fraunhofer Institute for Applied Solid State Physics, Freiburg, Germany, for providing the IR laser for the experiments. We thank Martin Ebert (Technical University Darmstadt) for the Etna ash sample. Erik Hermann (Paul Scherrer Institut) is acknowledged for providing the APS, and Günther Wehrle (Paul Scherrer Institut) for the fruitful discussions.

Edited by: F. Prata

\section{References}

Beswick, K., Baumgardner, D., Gallagher, M., Volz-Thomas, A., Nedelec, P., Wang, K.-Y., and Lance, S.: The backscatter cloud probe - a compact low-profile autonomous optical spectrometer, Atmos. Meas. Tech., 7, 1443-1457, doi:10.5194/amt-7-14432014, 2014.

Binnig, J., Meyer, J., and Kasper, G.: Calibration of an optical particle counter to provide mass for well-defined particle materials, J. Aerosol Sci., 38, 325-332, doi:10.1016/j.jaerosci.2006.12.001, 2007.

Bohren, C. and Huffman, D.: Absorption and Scattering of Light by Small Particles, Wiley-VCH, Weinheim, Germany, 82-129, 2004.

Brabec, M., Wienhold, F. G., Luo, B. P., Vömel, H., Immler, F., Steiner, P., Hausammann, E., Weers, U., and Peter, T.: Particle backscatter and relative humidity measured across cirrus clouds and comparison with microphysical cirrus modelling, Atmos. Chem. Phys., 12, 9135-9148, doi:10.5194/acp-12-9135-2012, 2012.
Bukowiecki, N., Zieger, P., Weingartner, E., Jurányi, Z., Gysel, M., Neininger, B., Schneider, B., Hueglin, C., Ulrich, A., Wichser, A., Henne, S., Brunner, D., Kaegi, R., Schwikowski, M., Tobler, L., Wienhold, F. G., Engel, I., Buchmann, B., Peter, T., and Baltensperger, U.: Ground-based and airborne in-situ measurements of the Eyjafjallajökull volcanic aerosol plume in Switzerland in spring 2010, Atmos. Chem. Phys., 11, 10011-10030, doi:10.5194/acp-11-10011-2011, 2011.

Casadevall, T. J.: Volcanic hazards and aviation safety, lessons of the past decade, FAA Aviation Safety Journal, 2, 9-17, 1993.

Cirisan, A., Luo, B. P., Engel, I., Wienhold, F. G., Sprenger, M., Krieger, U. K., Weers, U., Romanens, G., Levrat, G., Jeannet, P., Ruffieux, D., Philipona, R., Calpini, B., Spichtinger, P., and Peter, T.: Balloon-borne match measurements of midlatitude cirrus clouds, Atmos. Chem. Phys., 14, 7341-7365, doi:10.5194/acp14-7341-2014, 2014.

Coz, E., Gómez-Moreno, F. J., Casuccio, G. S., and Artíñano, B. N.: Variations on morphology and elemental composition of mineral dust particles from local, regional, and long-range transport meteorological scenarios, J. Geophys. Res-Atmos., 115, D12204, doi:10.1029/2009JD012796, 2010.

Cozic, J., Verheggen, B., Weingartner, E., Crosier, J., Bower, K. N., Flynn, M., Coe, H., Henning, S., Steinbacher, M., Henne, S., Collaud Coen, M., Petzold, A., and Baltensperger, U.: Chemical composition of free tropospheric aerosol for PM1 and coarse mode at the high alpine site Jungfraujoch, Atmos. Chem. Phys., 8, 407-423, doi:10.5194/acp-8-407-2008, 2008.

Curtis, D. B., Meland, B., Aycibin, M., Arnold, N. P., Grassian, V. H., Young, M. A., and Kleiber, P. D.: A laboratory investigation of light scattering from representative components of mineral dust aerosol at a wavelength of $550 \mathrm{~nm}$, J. Geophys. ResAtmos., 113, D08210, doi:10.1029/2007JD009387, 2008.

Di Biagio, C., Boucher, H., Caquineau, S., Chevaillier, S., Cuesta, J., and Formenti, P.: Variability of the infrared complex refractive index of African mineral dust: experimental estimation and implications for radiative transfer and satellite remote sensing, Atmos. Chem. Phys., 14, 11093-11116, doi:10.5194/acp14-11093-2014, 2014.

Dick, W. D., McMurry, P. H., and Bottiger, J. R.: Size and composition-dependent response of the DAWN - a multiangle single-particle optical detector, Aerosol Sci. Tech., 20, 345-362, doi:10.1080/02786829408959690, 1994.

Glen, A. and Brooks, S. D.: A new method for measuring optical scattering properties of atmospherically relevant dusts using the Cloud and Aerosol Spectrometer with Polarization (CASPOL), Atmos. Chem. Phys., 13, 1345-1356, doi:10.5194/acp-13-13452013, 2013.

Grainger, R. G., Peters, D. M., Thomas, G. E., Smith, A. J. A., Siddans, R., Carboni, E., and Dudhia, A.: Measuring volcanic plume and ash properties from space, Geol. Soc. SP, 380, 293 320, doi:10.1144/SP380.7, 2013.

Groß, S., Esselborn, M., Weinzierl, B., Wirth, M., Fix, A., and Petzold, A.: Aerosol classification by airborne high spectral resolution lidar observations, Atmos. Chem. Phys., 13, 2487-2505, doi:10.5194/acp-13-2487-2013, 2013.

Kerker, M.: Light scattering instrumentation for aerosol studies: an historical overview, Aerosol Sci. Tech., 38, 522-540, doi:10.1080/02786829708965492, 1997. 
Kobayashi, H., Hayashi, M., Shiraishi, K., Nakura, Y., Enomoto, T., Miura, K., Takahashi, H., Igarashi, Y., Naoe, H., Kaneyasu, N., Nishizawa, T., and Sugimoto, N.: Development of a polarization optical particle counter capable of aerosol type classification, Atmos. Environ., 97, 486-492, doi:10.1016/j.atmosenv.2014.05.006, 2014.

Koepke, P., Hess, M., Schult, I., and Shettle, E. P.: Global Aerosol Data Set, Report No. 243, Max-Planck-Institut für Meteorologie, Hamburg, Germany, p. 37, 1997.

Merikallio, S., Muñoz, O.,Sundström, A.-M., Virtanen, T., H., Horttanainen, M., de Leeuw, G., Nousiainen, T.: Optical modeling of volcanic ash particles using ellipsoids, J. Geophys. Res.-Atmos., 120, 4102-4116, doi:doi:10.1002/2014JD022792, 2015.

Muñoz, O., and Hovenier, J. W.: Laboratory measurements of single light scattering by ensembles of randomly oriented small irregular particles in air. Areview, J. Quant. Spectrosc. Ra., 112, 1646-1657, doi:10.1016/j.jqsrt.2011.02.005, 2011.

Nagy, A., Szymanski, W., Gál, P., Golczewski, A., and Czitrovszky, A.: Numerical and experimental study of the performance of the dual wavelength optical particle spectrometer (DWOPS), J. Aerosol Sci., 38, 467-478, doi:10.1016/j.jaerosci.2007.02.005, 2007.

Petzold, A., Rasp, K., Weinzierl, B., Esselborn, M., Hamburger, T., Dörnbrack, A., Kandler, K., Schütz, L., Knippertz, P., Fiebig, M., and Virkkula, A.: Saharan dust absorption and refractive index from aircraft-based observations during SAMUM 2006, Tellus B, 61, doi:10.1111/j.1600-0889.2008.00383.x, 2011.

Pollack, J. B., Toon, O. B., and Khare, B. N.: Optical properties of some terrestrial rocks and glasses, Icarus, 19, 372-389, doi:10.1016/0019-1035(73)90115-2, 1973.

Rosen, J. M.: The vertical distribution of dust to 30 Kilometers, J. Geophys. Res., 69, 4673-4676, 1964.

Rosen, J. M., Kjome, N., T.: Backscattersonde: a new instrument for atmospheric aerosol research, Appl. Optics, 30, 1552-1561, 1991.

Rothman, L., Gordon, I., Babikov, Y., Barbe, A., Benner, D. C., Bernath, P., Birk, M., Bizzocchi, L., Boudon, V., Brown, L., Campargue, A., Chance, K., Cohen, E., Coudert, L., Devi, V., Drouin, B., Fayt, A., Flaud, J.-M., Gamache, R., Harrison, J., Hartmann, J.-M., Hill, C., Hodges, J., Jacquemart, D., Jolly, A., Lamouroux, J., Roy, R. L., Li, G., Long, D., Lyulin, O., Mackie, C., Massie, S., Mikhailenko, S., Müller, H., Naumenko, O., Nikitin, A., Orphal, J., Perevalov, V., Perrin, A., Polovtseva, E., Richard, C., Smith, M., Starikova, E., Sung, K., Tashkun, S., Tennyson, J., Toon, G., Tyuterev, V., and Wagner, G.: The HITRAN2012 molecular spectroscopic database, J. Quant. Spectrosc. Ra., 130, 4-50, doi:10.1016/j.jqsrt.2013.07.002, 2013.
Schumann, U., Weinzierl, B., Reitebuch, O., Schlager, H., Minikin, A., Forster, C., Baumann, R., Sailer, T., Graf, K., Mannstein, H., Voigt, C., Rahm, S., Simmet, R., Scheibe, M., Lichtenstern, M., Stock, P., Rüba, H., Schäuble, D., Tafferner, A., Rautenhaus, M., Gerz, T., Ziereis, H., Krautstrunk, M., Mallaun, C., Gayet, J.F., Lieke, K., Kandler, K., Ebert, M., Weinbruch, S., Stohl, A., Gasteiger, J., Groß, S., Freudenthaler, V., Wiegner, M., Ansmann, A., Tesche, M., Olafsson, H., and Sturm, K.: Airborne observations of the Eyjafjalla volcano ash cloud over Europe during air space closure in April and May 2010, Atmos. Chem. Phys., 11, 2245-2279, doi:10.5194/acp-11-2245-2011, 2011.

Szymanski, W. W., Nagy, A., Czitrovszky, A., and Jani, P.: A new method for the simultaneous measurement of aerosol particle size, complex refractive index and particle density, Meas. Sci. Technol., 13, 303-307, doi:10.1088/0957-0233/13/3/311, 2002.

Turnbull, K., Johnson, B., Marenco, F., Haywood, J., Minikin, A., Weinzierl, B., Schlager, H., Schumann, U., Leadbetter, S., Woolley, A.: A case study of observations of volcanic ash from the Eyjafjallajökull eruption: 1. In situ airborne observations, J. Geophys. Res., 117, D00U12, doi:10.1029/2011JD016688, 2012.

Volz, F. E.: Infrared optical constants of ammonium sulfate, Sahara dust, volcanic pumice, and flyash, Appl. Optics, 12, 564-568, doi:10.1364/AO.12.000564, 1973.

Weinzierl, B., Sauer, D., Minikin, A., Reitebuch, O., Dahlkötter, F., Mayer, B., Emde, C., Tegen, I., Gasteiger, J., Petzold, A., Veira, A., Kueppers, U., and Schumann, U.: On the visibility of airborne volcanic ash and mineral dust from the pilot's perspective in flight, Phyis. Chem. Earth, 45-46, 87-102, doi:10.1016/j.pce.2012.04.003, 2012.

Yurkin, M., A., Hoekstra, A., G.: The discrete-dipoleapproximation code ADDA: Capabilities and known limitations, J. Quant. Spectrosc. Ra., 112, 2234-2247, doi:10.1016/j.jqsrt.2011.01.031, 2011. 